Jurnal Ilmu Ilmu Agribisnis: Journal of Agribusiness Science, 9(2), Mei 2021

\title{
ANALISIS KERAGAAN AGROINDUSTRI KLANTING DI DESA GANTIMULYO KECAMATAN PEKALONGAN KABUPATEN LAMPUNG TIMUR
}

\author{
(The Performance of Klanting Agroindustry in Gantimulyo Village Pekalongan Subdistrict \\ East Lampung Regency)
}

Gusti Ayu Komang Theresia Aidawati, Ktut Murniati, Maya Riantini

\begin{abstract}
Jurusan Agribisnis, Fakultas Pertanian, Universitas Lampung, Jl. Prof. Dr. Soemantri Brodjonegoro No. 1
Bandar Lampung 35145,e-mail: ktut.murniati @fp.unila.ac.id
\end{abstract}

\begin{abstract}
This research aims to analyze the procurement process of raw materials that correspond to six rights (time, place, quality, quantity, type, and price), klanting agroindustry profit, and marketing mix with $7 P$ (product, price, promotion, place, people (human resources), process, and physical evidence). This research uses the case study method at Klanting Agrondustry in Gantimulyo Village Pekalongan District. The location was chosen purposively considering that the village is a klanting production center in East Lampung Regency. Data of this research were collected from December 2019 to January 2020. The method data analysis used in this research is a descriptive qualitative analysis and quantitative. The results of this research indicated that the procurement of raw materials has not fulfilled all the six components precisely, because it does not match reality expected by agroindustry owners on components on time, the right type, right quality, and right quantity. On the right place and right price component, it is accordance with the agroindustry owner's expectations, because the location of raw materials is close to the agroindustry, and the price is low. The advantages of agroindustry are good, because it shows a positive advantage. That advantage obtained in one month at Mekar Sari Agroindustry amounting to IDR4,933,709.57, Mitra Tani Agroindustry amounting to IDR3,854,706.64, and Mitra Lestari Agroindustry IDR2,907,475.87. The agroindustry marketing strategy has implemented components of the 7P marketing mix, only the promotional components are missing applied optimally.
\end{abstract}

Key words: agroindustry, klanting, marketing mix, performance

\section{PENDAHULUAN}

Agroindutri merupakan industri yang bahan baku utamanya berupa produk hasil pertanian. Agroindustri merupakan lanjutan dari tahapan pembangunan pertanian, namun belum sampai ke tahap pembangunan industri. Peran agroindustri sangat penting dalam usaha pembangunan pertanian. Hal tersebut terlihat dari kontribusinya dalam meningkatkan pendapatan pelaku agribisnis, penyerapan tenaga kerja, peningkatan devisa negara, dan mendorong tumbuhnya industri lain (Soekartawi 2000).

Pengembangan agroindustri sangat penting untuk diperhatikan, karena dapat menunjang pembangunan pertanian yang maju dan efisien. Agroindustri berpengaruh terhadap pengembangan ekonomi dan kesejahteraan masyarakat, dengan melihat besarnya potensi dari adanya agroindustri maka dapat memberikan peluang bagi pelaku bisnis untuk meningkatkan dan melaksanakan pembangunan pertanian. Ubi kayu merupakan salah satu komoditas yang banyak digunakan sebagai bahan baku agroindustri di Indonesia.

Pelaku agroindustri dapat memperoleh bahan baku ubi kayu dengan mudah, karena ubi kayu dapat tumbuh pada berbagai ekosistem. Pada periode tahun 2012-2016, Indonesia mengalami peningkatan perkembangan produktivitas ubi kayu sebesar 2,85 persen per tahun. Ubi kayu juga menjadi salah satu fokus kebijakan pertanian 20152019 karena memiliki potensi yang baik dan berkelanjutan sebagai komoditas pangan maupun non pangan.

Kabupaten Lampung Timur memiliki potensi yang besar dalam pengembangan agroindustri klanting di Provinsi Lampung, terbukti dari jumlah produksi ubi kayu atau singkong di Kabupaten Lampung Timur pada tahun 2017 mencapai 1.096.905 ton dan memiliki luas areal tanam sebesar 36.541 ha (BPS Lampung Timur 2018).

Sektor industri pengolahan memiliki kontribusi yang cukup besar terhadap Produk Domestik 
Regional Bruto (PDRB) Kabupaten Lampung Timur, namun industri pengolahan mengalami pertumbuhan yang berfluktuatif. Kontribusi industri olahan terhadap perekonomian Lampung Timur sebesar 6,31 persen sampai dengan 7,42 persen selama 2013-2017 (BPS Lampung Timur 2018).

Agroindustri klanting merupakan bidang usaha yang banyak dikembangkan di Kecamatan Pekalongan, Kabupaten Lampung Timur. Industri tersebut memanfaatkan ubi kayu sebagai bahan baku untuk diolah menjadi klanting yang bernilai tambah. Permasalahan yang sering dihadapi industri tersebut adalah ketersediaan bahan baku yang fluktuatif atau tidak stabil, sehingga mempengaruhi kinerja usaha agroindustri. Penelitian ini bertujuan untuk menganalisis pengadaan bahan baku, keuntungan, dan bauran pemasaran pada agroindustri klanting.

\section{METODE PENELITIAN}

Metode penelitian yang digunakan dalam penelitian ini adalah metode studi kasus pada tiga agroindustri klanting yang dipilih berdasarkan kapasitas produksinya. Agroindustri Mekar Sari dengan kapasitas produksi terbesar, Agroindustri Mitra Tani dengan kapasitas produksi menengah, dan Agroindustri Mitra Lestari dengan kapasitas produksi terkecil. Lokasi penelitian dipilih secara sengaja (purposive) dengan pertimbangan bahwa Desa Gantimulyo merupakan sentra produksi klanting di Kabupaten Lampung Timur.

Pengambilan sampel konsumen menggunakan metode accidental sampling, yang bertujuan untuk mengetahui efektivitas bauran pemasaran. Responden yang dipilih dalam penelitian ini adalah konsumen yang secara kebetulan datang ke lokasi penelitian (Notoatmodjo 2010). Pengumpulan data dilakukan pada bulan Desember 2019 - Januari 2020 .

Penelitian ini menggunakan data primer dan data sekunder. Data primer merupakan data yang diperoleh melalui wawancara dengan pihak agroindustri klanting dan melakukan pengamatan secara langsung atau melalui observasi. Data sekunder merupakan data yang diperoleh berdasarkan literatur-literatur yang berhubungan dengan penelitian dan data dari agroindustri, serta data yang dikutip dari instansi-instansi terkait seperti BPS.
Metode analisis data yang digunakan pada penelitian ini adalah metode analisis deskriptif kualitatif dan analisis deskriptif kuantitatif. Analisis deskriptif kualitatif digunakan untuk menganalisis pengadaan bahan baku dan bauran pemasaran, sedangkan analisis deskriptif kuantitatif digunakan untuk menganalisis pendapatan usaha.

Analisis deskriptif kualitatif digunakan untuk menganalisis manajemen pengadaan bahan baku dan bauran pemasaran. Dalam pengadaan bahan baku, analisis deskriptif kualitatif digunakan untuk menganalisis permasalahan serta cara mengatasi permasalahan tersebut. Pada bauran pemasaran bertujuan untuk menganalisis penerapan bauran pemasaran pada agroindustri klanting yaitu berupa 7P (Place, Price, Place, Promotion, People, Process, Physical Evidence) serta untuk mengetahui permasalahan yang terjadi dalam proses pemasaran klanting, baik dari bauran pemasaran dan langkah yang dilakukan untuk mengatasi permasalahan tersebut (Martjiono 2014).

Analisis pendapatan digunakan untuk menganalisis tujuan kedua. Analisis pendapatan digunakan untuk melihat seberapa besar pendapatan yang diperoleh agroindustri klanting dan untuk melihat apakah agroindustri tersebut layak untuk diusahakan berdasarkan nilai R/C. Analisis pendapatan secara matematis dapat dirumuskan sebagai berikut:

$\pi=\mathrm{TR}-\mathrm{TC}$

$\pi=(\mathrm{Y} . \mathrm{Py})-(\mathrm{X} . \mathrm{Px})$

Keterangan:

$\pi \quad=$ Keuntungan $(\mathrm{Rp})$

$\mathrm{TR}=$ Total penerimaan $(\mathrm{Rp})$

$\mathrm{TC}=$ Total biaya $(\mathrm{Rp})$

$\mathrm{Y} \quad=$ Hasil produksi $(\mathrm{kg})$

Py = Harga satuan produksi $(\mathrm{Rp})$

$\mathrm{X} \quad=$ Faktor produksi $(\mathrm{i}=1,2,3, \ldots ., \mathrm{n})$

$\mathrm{Px} \quad=$ Harga faktor produksi ke-i $(\mathrm{Rp})$

BTT = biaya tetap total $(\mathrm{Rp})$

Kriteria pegambilan keputusan adalah:

a. Jika R/C >1, maka usaha mengalami keuntungan, karena penerimaan lebih besar dari biaya.

b. Jika $\mathrm{R} / \mathrm{C}<1$, maka usaha mengalami kerugian, karena penerimaan lebih kecil dari biaya.

c. Jika $\mathrm{R} / \mathrm{C}=1$, maka usaha mengalami impas, karena penerimaan sama dengan biaya. 
Jurnal Ilmu Ilmu Agribisnis: Journal of Agribusiness Science, 9(2), Mei 2021

\section{HASIL DAN PEMBAHASAN}

\section{Karakteristik Responden Pemilik Agroindustri dan Konsumen}

Jumlah agroindustri yang dipilih dalam penelitian ini sebanyak tiga agroindustri. Kapasitas produksi terbesar adalah Agroindustri Mekar Sari, pemiliknya bernama Bapak Sugiarto yang berumur 47 tahun dengan tingkat pendidikan terakhir SMK. Jumlah tanggungan keluarga yaitu tiga orang. Agroindustri ini telah berjalan selama 23 tahun. Agroindustri dengan kapasitas produksi menengah adalah Agroindustri Mitra Tani, pemiliknya bernama Bapak Ponimin yang berumur 50 tahun dengan tingkat pendidikan terakhir SLTA. Jumlah tanggungan keluarga yaitu tiga orang. Agroindustri ini telah berjalan selama 15 tahun. Agroindustri dengan kapasitas produksi terkecil adalah Agroindustri Mitra Lestari, pemiliknya bernama Bapak Saiman yang berumur 54 tahun dengan tingkat pendidikan terakhir SLTA. Jumlah tanggungan keluarga yaitu dua orang. Agroindustri ini telah berjalan selama 12 tahun.

Responden konsumen klanting didominasi oleh konsumen dengan jenis kelamin laki-laki, dengan usia produktif yaitu dengan persentase usia 15-30 tahun sebanyak 42 persen, 31-50 tahun sebanyak 50 persen dan $>50$ tahun sebanyak 8 persen. Tingkat pendidikan konsumen agroindustri mayoritas adalah lulusan SMA yaitu sebanyak 50 persen. Pendapatan rumah tangga konsumen sebagian besar berkisar antara Rp1.000.000,00 sampai Rp2.000.000,00.

\section{Pengadaan Bahan Baku pada Agroindustri}

Bahan baku merupakan faktor penting yang dapat menunjang keberhasilan agroindustri. Terpenuhinya bahan baku yang cukup dan berkelanjutan akan berpengaruh pada jumlah keluaran yang dihasilkan agroindustri. Manajemen yang baik diperlukan dalam pelaksanaan pemenuhan bahan baku agar diperoleh keluaran sesuai dengan keinginan agroindustri. Kegiatan pengadaan bahan baku bertujuan menunjang jalannya proses produksi pada agroindustri. Menurut Indrajit dan Djokopranoto (2003) pengadaan bahan baku berfungsi untuk menyediakan bahan baku yang sesuai dengan 6 tepat, yaitu dengan waktu yang tepat, kualitas yang baik dan tersedia secara berkesinambungan dengan biaya yang layak, dan jenis yang tepat. Pengadaan bahan baku dapat dilihat pada Tabel 1 ..

\begin{tabular}{|c|c|c|}
\hline 6 Tepat & Harapan & Kenyataan \\
\hline Waktu & $\begin{array}{l}\text { Pengadaan bahan } \\
\text { baku dapat } \\
\text { tersedia saat } \\
\text { melaksanakan } \\
\text { kegiatan produksi, } \\
\text { dan tepat waktu } \\
\text { pada saat } \\
\text { pengiriman. }\end{array}$ & $\begin{array}{l}\text { Bahan baku tidak } \\
\text { selalu tersedia } \\
\text { saat dibutuhkan, } \\
\text { agroindustri. }\end{array}$ \\
\hline Tempat & $\begin{array}{l}\text { Tempat pemasok } \\
\text { bahan baku yang } \\
\text { terjangkau oleh } \\
\text { agroindustri } \\
\text { klanting. }\end{array}$ & $\begin{array}{l}\text { Pemasok bahan } \\
\text { baku dekat } \\
\text { dengan } \\
\text { agroindustri. }\end{array}$ \\
\hline Jenis & $\begin{array}{l}\text { Jenis ubi kayu } \\
\text { yang dikirimkan } \\
\text { pemasok yaitu } \\
\text { jenis singkong } \\
\text { makan. }\end{array}$ & $\begin{array}{l}\text { Jenis ubi kayu } \\
\text { yang dikirimkan } \\
\text { pemasok tidak } \\
\text { selalu singkong } \\
\text { makan. }\end{array}$ \\
\hline Kualitas & $\begin{array}{l}\text { Bahan baku } \\
\text { memiliki sedikit } \\
\text { kadar air, daging } \\
\text { ubi berwarna putih } \\
\text { dan tidak rusak. }\end{array}$ & $\begin{array}{l}\text { Bahan baku yang } \\
\text { dikirimkan tidak } \\
\text { selalu memiliki } \\
\text { kualitas yang } \\
\text { baik. }\end{array}$ \\
\hline Kuantitas & $\begin{array}{l}\text { Jumlah bahan } \\
\text { baku ubi kayu } \\
\text { yang dipesan } \\
\text { sesuai dengan } \\
\text { yang dikirimkan. }\end{array}$ & $\begin{array}{l}\text { Pemasok } \\
\text { terkadang tidak } \\
\text { dapat } \\
\text { menyediakan } \\
\text { bahan baku } \\
\text { sesuai pesanan. }\end{array}$ \\
\hline Harga & $\begin{array}{l}\text { Harga bahan baku } \\
\text { ubi kayu tidak } \\
\text { terlalu tinggi dan } \\
\text { diharapkan tidak } \\
\text { ada kenaikan } \\
\text { harga. }\end{array}$ & $\begin{array}{l}\text { Harga bahan } \\
\text { baku murah serta } \\
\text { jarang terjadi } \\
\text { kenaikan harga. }\end{array}$ \\
\hline
\end{tabular}

Penelitian ini sejalan dengan hasil penelitian Kusuma, Widjaya, dan Situmorang (2019) dimana analisis pengadaan bahan baku pada penelitian tersebut menggunakan metode 6 tapat pada penelitian tersebut sesuai dengan harapan pemilik agroindustri, hal ini sesuai dengan komponen harga pada agroindustri klanting di Desa Gantimulyo.

\section{Analisis Keuntungan}

Pendapatan yang diperoleh Agroindustri Mekar Sari dalam sebulan atau 4 kali produksi adalah sebesar Rp15.000.000,00. Keuntungan atas biaya total sebesar Rp4.933.709,57. Pendapatan yang diperoleh adalah Rp10.500.000,00, keuntungan atas biaya total sebesar Rp3.854.706,64 meskipun penggunaan bahan baku yang digunakan pada 
Agroindustri Mitra Tani lebih besar dibanding dengan bahan baku yang digunakan oleh Agroindustri Mitra Lestari, namun keuntungan yang dihasilkan tidak jauh berbeda. Pendapatam Agroindustri Mitra Lestari sebesar Rp7.560.000,00 dengan keuntungan atas biaya total sebesar Rp2.907.475,87. Penggunaan bahan baku dengan harga lebih tinggi dibandingkan dengan kedua agroindustri lainnya menjadi salah satu faktor yang menyebabkan keuntungan Agroindustri Mitra Tani dan Mitra Lestari tidak jauh berbeda. Selain itu, pada saat penelitian hasil produksi Agroindustri Mitra Tani mengalami penurunan yang disebabkan oleh tingginya kadar air ubi kayu. Hal tersebut menyebabkan klanting yang dihasilkan lebih sedikit dari yang seharusnya.

Penelitian ini sejalan dengan Syarief, Lestari, dan Kasymir (2019) mengenai keragaan agroindustri Kerupuk Bawang, hasil penelitian tersebut menunjukkan bahwa agroindustri kerupuk juga sudah menguntungkan dan layak diusahakan. Hal ini sesuai dengan usaha klanting pada agroindustri klanting dalam penelitian ini. Hasil penelitian juga sejalan dengan penelitian Evina (2017) dimana penelitian tersebut menunjukan suatu agroindustri akan memperoleh keuntungan yang lebih besar apabila menggunakan bahan baku yang berkualitas baik serta memiliki jumlah produksi tinggi. Hal ini sesuai dengan usaha klanting pada Agroindustri Mekar Sari, Mitra Tani, dan Mitra Lestari. Keuntungan agroindustri klanting di Desa Gantimulyo dapat dilihat pada Tabel 2.

\section{Bauran Pemasaran}

Pemasaran merupakan kegiatan yang bertujuan untuk memenuhi permintaan konsumen akan produk atau barang dari produsen, serta melancarkan arus barang dari produsen ke konsumen. Untuk dapat mencapai keberhasilan pemasaran, setiap agroindustri harus menyusun strategi pemasaran yang efektif dengan menggunakan bauran pemasaran.

Tabel 2. Perhitungan pendapatan usaha pada agroindustri klanting di Desa Gantimulyo

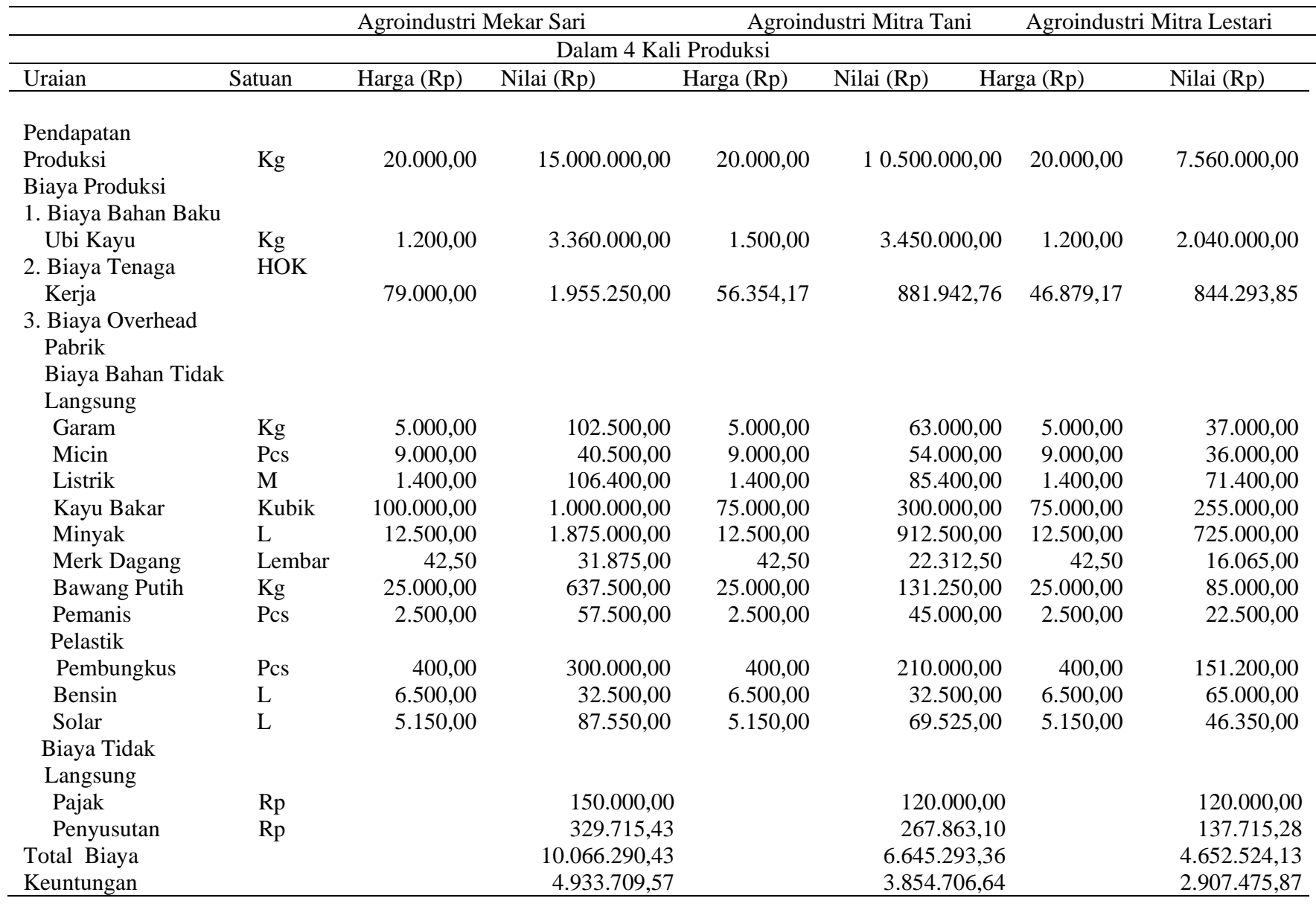


Komponen-komponen bauran pemasaran terdiri dari 7P yaitu product (produk), price (harga), place (lokasi atau distribusi), promotion (promosi) people (sumberdaya manusia), physical evidence (bukti fisik), dan process (proses). Bauran pemasaran produk klanting di Agroindustri Mekar Sari, Mitra Tani, dan Mitra Lestari menggunakan dua perspektif, yaitu perspektif pemilik agroindustri dan perspektif konsumen.

\section{1) Perspektif Pemilik Agroindustri}

Bauran pemasaran 7P yang telah diterapkan pemilik agroindustri klanting disajikan pada Tabel 3. Berdasarkan Tabel 3 dapat dilihat bahwa agroindustri klanting telah menerapkan tujuh komponen bauran pemasaran. Berdasarkan perspektif pemilik, komponen produk yang terdiri dari bentuk, ukuran, dan jumlah produksi kopi bubuk telah disesuaikan dengan permintaan konsumen. Harga klanting masih terjangkau di kalangan masyarakat dan pemilik menetapkan harga berdasarkan harga yang berlaku di pasar dan biaya produksi. Lokasi agroindustri letaknya sangat strategis, akan tetapi promosi yang diterapkan masih sangat minim dan hanya menggunakan metode personal selling, sehingga komponen promosi dapat dikategorikan kurang baik. Pemilik agroindustri telah melakukan manajemen karyawan yang baik. Karyawan telah melakukan proses pelayanan yang baik kepada konsumen, dan lingkungan agroindustri tertata rapi dan bersih.

Tabel 3. Bauran pemasaran berdasarkan perspektif pemilik agroindustri

\begin{tabular}{|c|c|c|c|}
\hline No & Komponen (Bauran Pemasaran 7P) & Agroindustri Klanting & Harapan \\
\hline 1 & $\begin{array}{l}\text { Produk } \\
\text { a. Kualitas, Jumlah, dan Tampilan } \\
\text { b. Bentuk kemasan }\end{array}$ & $\begin{array}{l}\text { a. Sesuai dengan permintaan } \\
\text { konsumen } \\
\text { b. Plastik Pembungkus, namun belum } \\
\text { sesuai dengan keinginan konsumen } \\
\text { c. Sudah terdapat merek (Cap dagang) } \\
\text { d. } 5 \text { bulan }\end{array}$ & $\begin{array}{l}\text { Pengemasan lebih menarik, dan } \\
\text { tersedia dalam berbagai ukuran } \\
\text { kemasan sesuai dengan } \\
\text { kekeinginan konsumen }\end{array}$ \\
\hline 2 & $\begin{array}{l}\text { Harga } \\
\text { a. Penetapan Harga } \\
\text { b. Harga Klanting } \\
\text { c. Cara Pembayaran }\end{array}$ & $\begin{array}{l}\text { a. Berdasarkan harga yang berlaku dan } \\
\text { biaya produksi } \\
\text { b. Terjangkau } \\
\text { c. Secara tunai, namun belum dapat } \\
\text { mempermudah konsumen dalam } \\
\text { melakukan pembayaran. }\end{array}$ & $\begin{array}{l}\text { Memberikan fasilitas } \\
\text { pembayaran secara debit atau } \\
\text { pembayaran elektronik untuk } \\
\text { mempermudah konsumen. }\end{array}$ \\
\hline 3 & $\begin{array}{ll}\text { b. } & \text { Sasaran Pemasaran } \\
\text { c. } & \text { Tempat Pemasaran } \\
\text { d. } & \text { Lokasi Agroindustri }\end{array}$ & $\begin{array}{l}\text { a. Dipasarkan secara langsung, serta } \\
\text { melalui agen, namun kegiatan } \\
\text { pemasaran masih kurang luas } \\
\text { b. Masyarakat umum } \\
\text { c. Agen dan lokasi agroindustri } \\
\text { d. Strategis }\end{array}$ & $\begin{array}{l}\text { Dilakukan pemasaran secara } \\
\text { online untuk memperluas } \\
\text { pemasaran klanting. }\end{array}$ \\
\hline 4 & $\begin{array}{l}\text { Promosi } \\
\quad \text { Kegiatan Promosi }\end{array}$ & Melalui personal selling & $\begin{array}{l}\text { Dilakukan promosi yang lebih } \\
\text { bervariasi seperti melalui media } \\
\text { sosial. }\end{array}$ \\
\hline 5 & $\begin{array}{l}\text { Sumberdaya Manusia } \\
\text { a. Pembagian Kerja } \\
\text { b. Motivasi Kerja } \\
\text { c. Penghargaan Karyawan }\end{array}$ & $\begin{array}{l}\text { a. Sesuai dengan kemampuan } \\
\text { karyawan } \\
\text { b. Menjalin komunikasi dan peduli } \\
\text { terhadap karyawan } \\
\text { c. Pemberian upah yang sesuai }\end{array}$ & $\begin{array}{l}\text { Pemberian bonus untuk } \\
\text { karyawan yang handal dan tekun } \\
\text { agar lebih bersemangat dalam } \\
\text { melaksanakan tugasnya }\end{array}$ \\
\hline 6 & $\begin{array}{l}\text { Proses } \\
\text { a. Proses pelayanan } \\
\text { b. Proses pemesanan } \\
\text { c. Kopetensi Karyawan }\end{array}$ & $\begin{array}{l}\text { a. Lancar dan cepat } \\
\text { b. Melalu telepon dan diantarkan } \\
\text { c. Handal dan tangkas }\end{array}$ & $\begin{array}{l}\text { Memperluas pemesanan hingga } \\
\text { luar daerah untuk menambah } \\
\text { penjualan dan keuntungan. }\end{array}$ \\
\hline 7 & $\begin{array}{l}\text { Bukti Fisik } \\
\text { a. } \quad \text { Lingkungan } \\
\text { b. } \quad \text { Fasilitas Parkir } \\
\text { c. } \quad \text { Kerapian Produk }\end{array}$ & $\begin{array}{l}\text { a. Bersih dan luas } \\
\text { b. Tersedia } \\
\text { c. Tertata rapi }\end{array}$ & Membuat cabang penjualan \\
\hline
\end{tabular}


Tabel 4. Komponen bauran pemasaran pada agroindustri klanting berdasarkan perspektif konsumen

\begin{tabular}{clc}
\hline No & \multicolumn{1}{c}{ Komponen } & Rata-rata Persentase (\%) \\
\hline 1 & Produk & 81,33 \\
2 & Harga & 65,00 \\
3 & Tempat & 76,33 \\
4 & Promosi & 26,66 \\
5 & Sumberdaya manusia & 88,00 \\
6 & Proses & 73,00 \\
7 & Lingkungan fisik & 74,66 \\
\hline
\end{tabular}

\section{2) Perspektif Konsumen}

Berdasarkan perspektif konsumen klanting bahwa agroindustri telah menerapkan komponen bauran pemasaran dengan baik, kecuali pada komponen promosi. Hal ini sesuai dengan perspektif pemilik agroindustri, bahwa agroindustri klanting telah menerapkan bauran pemasaran dengan baik pada komponen produk, harga, tempat, sumberdaya manusia, proses, dan bukti fisik, akan tetapi pada komponen promosi, masih belum diterapkan dengan baik.

Tabel 4 menunjukkan bahwa komponen produk memperoleh skor tertinggi yaitu sebesar 81,33 persen. Menurut konsumen produk klanting yang ada di Desa Gantimulyo berbeda dari klanting biasanya, rasanyapun lebih renyah dan gurih serta dapat disimpan dalam waktu yang cukup lama. Komponen promosi memperoleh skor terendah yaitu sebesar 26,66 atau dapat dikategorikan kurang baik atau buruk. Hal ini karena media promosi yang diterapkan agroindustri masih sangat minim dan kurang bervariasi.

Agroindustri klanting hanya menerapkan metode personal selling atau dari mulut ke mulut untuk mempromosikan produknya. Hal ini tidak terlepas dari kendala biaya yang dimiliki agroindustri yang hanya diproritaskan untuk kegiatan produksi saja. Hal ini sejalan dengan penelitian Akbar, Lestari, dan Nugraha (2019) mengenai analisis keragaan agroindustri yang telah menerapkan bauran pemasaran dengan baik, akan tetapi pada komponen promotion masih masuk dalam kategori buruk dengan memperoleh skor nilai paling rendah.

\section{KESIMPULAN}

Pengadaan bahan baku Agroindustri Klanting di Desa Gantimulyo telah memenuhi kriteria tepat tempat dan tepat harga, namun belum memenuhi kriteria tepat jenis, tepat kualitas, tepat kuantitas, dan tepat waktu. Meskipun demikian, unit usaha tersebut menguntungkan. Strategi pemasaran lebih menekankan kepada bauran sumberdaya manusia, produk, tempat, lingkungan fisik, dan proses, namun bauran harga dan promosi belum menjadi prioritas dalam strategi pemasaran klanting.

\section{DAFTAR PUSTAKA}

Akbar TR, Lestari DAH, dan Nugraha A. 2019. Analisis keragaan dan risiko sistem agroindustri kopi bubuk (Studi kasus Agroindustri Kopi Bubuk Cap Obor Mas Lampung, Kecamatan Kotabumi Kota, Kabupaten Lampung Utara). Jurnal Ilmu Ilmu Agribisnis, $8(1)$ : 77-84. https://jurnal.fp.unila.ac.id/index.php/ JIA/article/view/3991/2904 [1 Juni 2020]

BPS [Badan Pusat Statistik] Kabupaten Lampung Timur. 2018. Kabupaten Lampung Timur dalam Angka. https://lampung.bps.go.id/ publication/2019/05/30/1da7f4de3b1cdb7204 039910 [25 Juni 2020].

Indrajit RE dan Djokopranoto R. 2003. Manajemen Persediaan, Barang Umum dan Suku Cadang Untuk Pemeliharaan dan Operasi. Grasindo. Jakarta.

Kusuma EW, Widjaya S, dan Situmorang S. 2020. Analisis pengadaan bahan baku dan nilai tambah agroindustri keripik ubi kayu di Kecamatan Way Jepara Kabupaten Lampung Timur. Jurnal Ilmu Ilmu Agribisnis, 8(1): 69$76 . \quad$ https: //jurnal.fp .unila.ac.id/index.Php/JIIA/article/view/3990/ 2903 [7 Juni 2020].

Martjiono. 2014. Analisa Pengaruh Bauran Pemasaran (7P) Terhadap Keputusan Pembelian di Rumah Makan Kakkk, Ayam Geprek. Skripsi. Universitas Kristen Petra. Surabaya.

Notoatmodjo S. 2010. Metodologi Penelitian Kesehatan. Rineka Cipta. Jakarta.

Soekartawi. 2000. Pengantar Agroindustri. PT Raja Grafindo Persada. Jakarta.

Syarief ANL, Lestari DAH, dan Kasymir E. 2019. Keragaan Agroindustri Kerupuk Bawang Winda Putri di Kecamatan Tanjung Senang Kota Bandar Lampung. Jurnal Ilmu Ilmu Agribisnis, $\quad$ 7(3): 298-305. https://jurnal.fp.unila.ac.id/index.php/JIA/artic le/view/3766/2767 [8 Juli 2020]. 